\title{
ENZYMATIC STUDY ON FOLIC ACID BIOSYNTHESIS BY MYCOBACTERIUM AVIUM
}

\author{
NOBUHIKO KATUNUMA, TORU SHODA, AND HIROKO NODA \\ Department of Biochemistry, School of Medicine Nagoya University, \\ Showa-ku, Nagoya
}

(Received January 30, 1957)

The relationship between purine biosynthesis and the action mechanism of $p$-aminosalicylic acid (PAS), an antimetabolite of tubercle bacilli, has hitherto been studied by the authors and the following findings have been obtained :

(a) 4-amino-5-imidazole carboxamide (AICA) ribotide, an intermediary metabolite of purine biosynthesis, and glycine-amide ribotide, a precursor of AICA ribotide, accumulate in the culture media of Mycobacterium avium, partially inhibited by PAS $(1,2)$. (b) A bacteriostatic action of PAS is weakened by purine derivatives, nucleic acids, and derivatives or components of cotransformylase, i.e., leucovorin, folic acid, $p$-aminobenzoylgutamate (PAG), and $p$-aminobenzoic acid (PABA) (1). (c) The accumulation of AICA derivatives fall by the above substances in spite of the existence of PAS, showing that PAS inhibits the biosynthesis of cotransformylase (3). (d) The biosynthetic pathway to cotransformylase is divided into two parts, i.e., that from folic acid to leucovorin and that up to folic acid. The former pathway was tested with the cell-free extract of this bacterium under the same condition as was performed by Doctor (4) and Nichol (5) and it was found that leucovorin was synthesized from folic acid in the yield of 20 per cent by this bacterium and the pathway was not inhibited at all by PAS (6). (e) The pathway up to folic acid has been studied by Wright and Welch (7), Forest-Walker (8) and Tsesche etal. It is now being clarified enzymatically by the authors that the folic acid biosynthesis starts with the synthesis of PAG, followed by the combination with pteridine. In the synthesis of PAG, i.e., peptide biosynthesis, a new finding was obtained concerning the activation of PABA by ATP and a mode of action by CoA. This mode of action is considered to be fairly universal in the systems in which $\mathrm{CoA}$ participates. It may also be considered to be a model experiment of protein synthesis. The mechanism of coupling with pteridine remains much to be settled.

Based upon these findings, the direct action point of PAS and sulfa drugs, as well as the mechanism of bacterial resistance, is now being studied by the authors. 


\section{EXPERIMENTAL}

\section{Extraction of Enzymes}

Mycobacterium avium (Jucho strain) was inoculated in a medium consisting $2 / 3$ volume of glycerol broth and $1 / 3$ volume of Sauton medium and cultured for 3-4 days. The cells harvisted were washed with Tris- $\mathrm{HCl}$ buffer and ground with an electric roll-mill for $3-4$ hours at $0^{\circ}$, keeping the $\mathrm{pH}$ at about 7.2 by adding Tris- $\mathrm{HCl}$ buffer ( $\mathrm{pH} 8.5)$. After centrifugation at 3000-4000 $\mathrm{rpm}$ for 5 minutes the supernatant is further centrifuged at $16000 \mathrm{rpm}$ for 30 minutes with a refrigerated high-speed centrifuge. The supernatant thus obtained was lyophilized. The lyophilized powder is called cell-free enzyme. This powder was dissolved in Tris-buffer. It was adjusted to $\mathrm{pH} 8.0$ and a $1 / 5$ volume of Amberlite IRA-400 (Cl-form, 200-400 mesh) was added. The mixture is stirred for $3-5$ minutes at below $0^{\circ}$ and is immediately centrifuged. The supernatatnt is reated once more with the resin and then lyophilized. The powder thus obtained is called resin-treated enzyme I. By this procedure, apoenzymes largely freed from cofactors are obtained, whereby the majority of folic acid and PABA pre-existed in the cells are adsorbed and removed, the determination becoming thus very easy. The loss of protein was found to be about $20-30$ per cent. The fractionation with acetone or ammonium sulfate proved to be unsuccessful due to denaturation of the enzyme.

\section{Conditions for Reactions}

p-Aminobenzoylglutamate Biosynthesis $\quad 1.05 \mathrm{~mm}$ of magnesium chloride, $2.4 \mathrm{~mm}$ of ATP-Na-salt, $1.2 \mathrm{~mm}$ of PABA $2.4 \mathrm{~mm}$ of L-glutamate and $20 \mathrm{mg} / \mathrm{ml}$

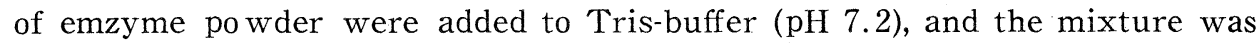
allowed to react for 3 - hours at $35^{\circ}$.

Folic Acid Biosynthesis-0.58 mm of PAG (or PABA) and $0.0558 \mathrm{~mm}$ of xanthopterin were added to $\mathrm{Mg}^{++}$-containing Tris-buffer. When PABA was used, $1.16 \mathrm{~mm}$ of L-glutamate was added in addition. After reaction for 3 hours, the mixture was heated for 5 minutes at $100^{\circ}$. The supernatant was adjusted to ca. $\mathrm{pH} 8.5$, an aliquot $(1 \mathrm{ml})$ was passed through a resin column and determined fractionally.

p-Aminobenzoyl Hydroxamate Formation - 28 per cent solution of hydroxylamine-HCI salt was neutralized with 14 per cent $\mathrm{NaOH}$ solution up to $\mathrm{pH}$ 7.2 , and the whole was added to $\mathrm{Mg}^{++}$-containing Tris-buffer $(\mathrm{pH} \mathrm{7.2)}$ in a volume of $1 / 5$. ATP and PABA were used. The reaction was continued for 30-90 minutes, followed by interruption with $\mathrm{HCl}$ or trichloroacetic acid (TCA). The hydroxamate was determined according to the Lipmann method (12).

\section{Determination Method}

$P A G$ - The product, PAG, can be separated from the substrate, PABA, by paper chromatography, and be determined by Diazo reaction. The deproteinized solution is lyophilized, dissolved in a little amount of water $(0.5 \mathrm{ml})$ and is developed with 5 per cent citrate-isoamyl alcohol according to Carter (9) or with acetic acid-butyl alcohol-water $(1: 4: 2)$. $R F$ of PAG, and PABA are 0.80 and 0.68 , respectively, with the former solvent, whereas 0.67 and 0.82 
with the latter one.

After color reaction with Diazo reagent using $N$-ethyleneamine, PAG was eluted with 10 per cent TCA-acetone $(25: 75)$ and was determined photometrically at $540 \mathrm{~m} \mu$.

Folic Acid-Deproteinized solution was adjusted to $\mathrm{pH} 8.5$ and was passed through an Amberlite IR-4B (Cl-form, 200-300 mesh) column. Xanthopterin was eluted with $0.25 M \mathrm{NaCl}$ solution. After $30 \mathrm{ml}$ being eluted it was made up to $0.70 \mathrm{M}$, whereby citrovorum factor (CF) was eluted. The elution of $\mathrm{CF}$ was completed after about $30 \mathrm{ml}$ has been passed through. Then, it was made up to $1.0 \mathrm{M}$, whereby folic acid was eluted. Each fraction was made $5 \mathrm{ml}$ and an adequate flow rate was found to be about $1 \mathrm{ml}$ per 10 minutes. $0.1-0.2 \mathrm{ml}$ from each fraction was mixed with $4 \mathrm{ml}$ of assay medium (11). Using Leuconostic citrovorum and Streptococcus faecalis, the vitamin was estimated nepherometrically.

Hydroxamic Acid Lipmann-Tuttle's method (12) was used.

\section{Results}

The pathway of folic acid biosynthesis was divided into two steps, i.e., coupling of glutamate with PABA and folic acid synthesis from PAG and xanthopterine.

\section{Biosynthesis of $P A G$}

Little PAG was formed when the resin-treated enzyme was incubated with PABA, L-glutamate, ATP and $\mathrm{Mg}^{++}$but the formation increased to four times, when CoA was further added (Fig. 1). When boiled extract was used, the yield increased to two times, far behind that with CoA. The maximum yield was about 25 per cent of the PABA added. This peptide linkage formation, therefore, takes place in the existence of ATP, CoA and $\mathrm{Mg}^{++}$. This reaction was strongly inhibited by pyrophosphoric acid as shown in the following experiment.

In the system shown in Table I, $1.2 \mathrm{~mm}$ of PABA, $2.4 \mathrm{~mm}$ of glutamate and

TABLE I

Biosynthesis of $P A C$

Reaction system consisting of

Enzyme : resin-treated $25 \mathrm{mg} / \mathrm{ml}$.

Substrate : PABA, $730 \mu \mathrm{n}$; L-glutamate $1460 \mu \mathrm{s}$.

Cofactors : CoA (75\% purity), $500 \mathrm{r} / \mathrm{ml}$; ATP, $4.2 \mathrm{~mm}$.

\begin{tabular}{c|c}
\hline Cofactor & Formed PAG \\
- & $\mu \mathbf{M}$ \\
Boiled extract & 52 \\
CoA & 130 \\
\end{tabular}

cell-free enzyme 1 were used and in addition, $0.6 \mathrm{~mm}$ of pyrophosphoric acid was added to a main test and an equimolecular concentration of $o$-phosphoric acid was added to a control test. After reaction, the formation of PAG in a main 


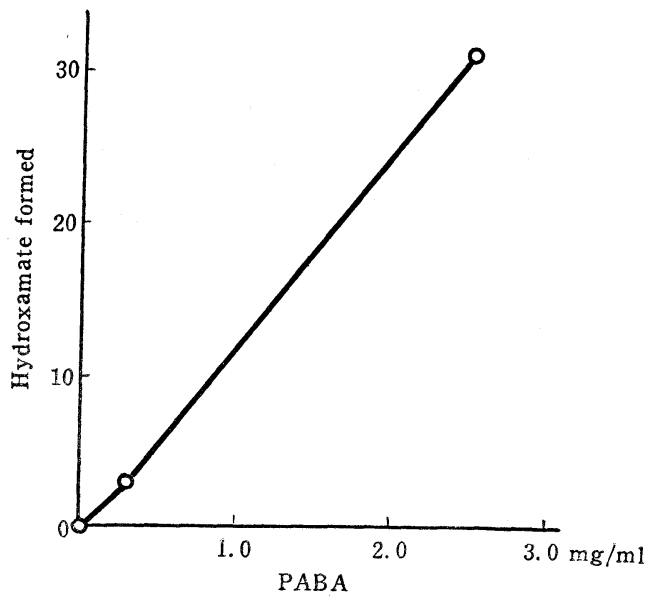

Fig. 1 Formation of p-Aminobenzoyl CoA $\mathrm{PABA}, 2.5$ and $0 \mathrm{mg} / \mathrm{ml}$; ATP, $4.2 \mathrm{~mm}$; $\mathrm{CoA}$, $60 \mathrm{I.U} . / \mathrm{ml}$; IRA-400 resin-treated enzyme powder, $15 \mathrm{mg} / \mathrm{ml}$ in final concentration. After reaction hydroxylamine was added, whereby the active intermediate was converted to hydroxamate, which was photometrically determined after adding $\mathrm{FeCl}_{3}$. test was $0.06 \mathrm{~mm}$, whereas that in a control was $0.18 \mathrm{~mm}$. It is suggested, therefore, that pyrophosphoric acid is liberated from ATP, whereby $p$-aminobenzoyl $\mathrm{CoA}$ is an active intermediate.

In the experiment shown in Fig. 1, sufficient amounts of $\mathrm{CoA}$ and ATP were added to the resintreated enzyme and varying amounts of PABA were further added but without glutamate. After reaction, the active intermediate formed was determined as hydroxamate according to Lipmann, the amount of the active intermediate formed was found to be directly proportional to the amount of PABA added. It was presumed, therefore, that the hydroxamate formed was $p$-aminobenzoyl hydroxamate (PA$\mathrm{BH})$. Furthermore, judging from the reaction condition, it was con-

sidered to be derived from $p$-aminobenzoyl CoA. Next, 5.6 per cent solution of hydroxylamine was added to the reaction system, and a similar experiment was conducted and the hydroxamate which was formed in the reaction was acidified with $\mathrm{HCl}$ and TCA and the colored solution after addition of ferric chloride was determined photometrically. In this case the amount of hydroxamate was proportionally increased to that of PABA. Of course, remarkably more hydroxamate formation was observed when hydroxylamine was added in the reaction system.

In a system of PABA, hydroxylamine and ATP, the PABH formation was strongly inhibited by pyrophosphoric acid, as shown in Table II. As stated

\section{TABLE II}

Inhibition of PABH Formation by Pyrophosphoric Acid and AMP

PABA, $7.3 \mathrm{~mm}$; ATP, $7.3 \mathrm{~mm}$; hydroxylamine, 5.6 per cent ; enzyme, (cell-free enzyme), $10.9 \mathrm{mg} / \mathrm{ml}$; after reaction for $1.5 \mathrm{hr}$, acidified, $\mathrm{FeCl}_{3}$ was added, and determined photometrically.

\begin{tabular}{c|c|c}
\hline Pyrophosphate & AMP & Hydroxamate \\
\hline- & - & 0.055 \\
+ & - & 0.000 \\
- & + & 0.040 \\
\hline
\end{tabular}

above, the biosynthesis of PAG was strongly inhibited by pyrophosphoric 
acid, and the affecting point of the inhibition is assumed from this experiment to be the formation of the active intermediate of $\mathrm{PABH}$. A weak inhibition by AMP was also observed, suggesting that pyrophosphoric acid and AMP were liberated prior to PABH formation.

Then, the pyrophosphoric acid liberated was determined according to Kornberg (13) and the AMP formed was determined by the optical density at $255 \mathrm{~m} \mu$ according to Umbreit (14), when $\mathrm{PABH}$ was formed in the reaction series which consists of PABA, ATP and hydroxylamine. As presented in Table III, the amounts increased of pyrophosphoric acid and AMP by the

TABLE III

Liberation of Pyrophosphate and $A M P$ in PABH Formation

PABA, $7.4 \mathrm{~mm}$; ATP-Na, $4 \mathrm{mg} / \mathrm{ml}$. Pyrophosphate was removed by preliminary treatment with $\mathrm{MnCl}_{2}$.

Enzyme, (cell-free enzyme) $17 \mathrm{mg} / \mathrm{ml}$. Reaction for $1 \mathrm{hr}$.

\begin{tabular}{c|c|c|c}
\hline PABA & Pyrophoshate & AMP & PABH (optical density) \\
\hline \multirow{2}{*}{} & $\mathrm{mM}$ & $\mathrm{mM}$ & 0.30 \\
Difference & 0.6 & 1.172 & 0.07 \\
\hline
\end{tabular}

addition of PABA were 0.3 and $0.288 \mathrm{~mm}$, respectively, indicating equimolecular liberation.

No pure synthetic PABH preparation being available in this experiment, PABH was expressed in the Table as optical densities estimated with Beckman Spectrophotometer.

From the above experiments, equlmolecular amounts of pyrophosphoric acid and AMP were found to be liberated in the $p$-aminobenzoyl CoA formation, possibly in the following reactions.

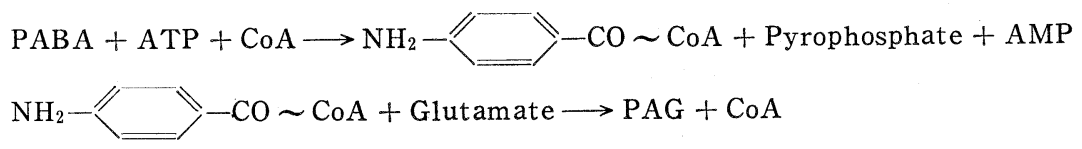

When the enzyme is treated with resin, the majority of CoA is removed by adsorption, as can be expected from literature (15), and the production of PAG is reduced to $1 / 4$ as mentioned above. Therefore, resin-treated enzyme was expected to produce less $\mathrm{PABH}$ in a system consisting of PABA, ATP and hydroxylamine than the enzyme rich in CoA. The result was however opposite, as shown in Table IV, viz., the activity was increased rather than decreased. Further, the addition of ATP and PABA is indispensable and both pyrophosphoric acid and AMP are liberated almost equimolecularly at $\mathrm{PABH}$ formation. The active intermediate derived from $\mathrm{PABA}$ which is capable of combining with hydroxylamineis therefore considered to be $p$ aminobenzoyl-AMP.

Assuming that $p$-aminobenzoyl-AMP is produced, as shown in Fig. 2, 
TABLE IV

PABH Formation with the Resin-Treated Enzyme

PABA, $4 \mathrm{mg} / \mathrm{ml}$; ATP- $\mathrm{Na}_{2}, 2.5 \mathrm{mg} / \mathrm{ml}$; hydroxylamine, 5.6 per cent. After reaction for $2 \mathrm{hr}$, acidified with $\mathrm{HCl}$ and TCA. Ferric chloride was added, and the color solution was determined photometrically.

\begin{tabular}{c|c|c|c}
\hline \multicolumn{1}{c|}{ Enzyme } & PABA & ATP & PABH/enzyme $(\mathrm{mg} / \mathrm{ml})$ \\
\hline \multirow{3}{*}{ Resin-treated enzyme 1 } & + & + & 0.150 \\
& - & + & 0.080 \\
& - & - & 0.005 \\
& + & - & 0.085 \\
\hline \multirow{2}{*}{ Non-treated enzyme 1 } & + & + & 0.130 \\
& - & + & 0.100 \\
& - & - & 0.010 \\
\hline
\end{tabular}

PABA is transferred from this intermediate, as well as from $p$-aminobenxoyl$\mathrm{CoA}$, to hydroxylamine, leading to $\mathrm{PABH}$ formation. The reason why $\mathrm{PABH}$ formation is not decreased even after removing $\mathrm{CoA}$ can thus be explained rationally. But the direct donor of active PABA, which forms PAG by transferring PABA to glutamate, must be $p$-aminobenzoyl-CoA, as clearly be seen from experimental data.

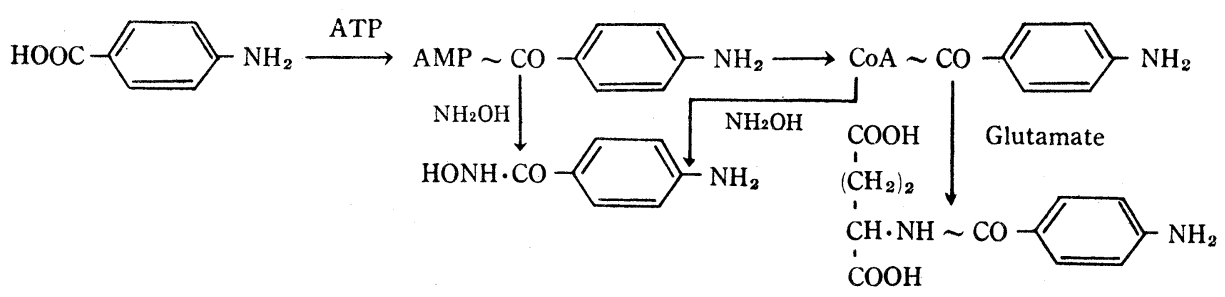

FIg. 2 Mechanism of PABH Formation

Therefore, the improved mechanism of this peptide formation, as presented in Fig. 3, is considered to be rational.

That the hydroxamate thus obtained is $\mathrm{PABH}$, is clear from experimental results. The chemically synthesized $\mathrm{PABH}$ by treating PABA-methyl ester with hydroxylamine showed the same $R \mathrm{~F}$ with the enzymatic reaction product in paper chromatogram. The identification of the enzymatic reaction product with $p$-aminobenzoyl-AMP and further enzymatic tests of this intermediate are now in progress.

2. Folic Acid Biosynthesis

For folic acid microbioassay Streptococus faecalis has hitherto been used but several folic acid derivatives occurring naturally have folic acid activity to the bacterium. The values determined with this bacterium are therefore 


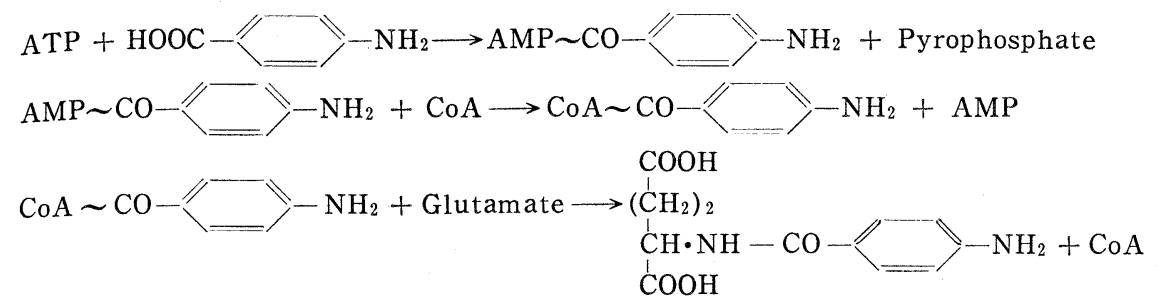

Fig. 3 Mechanism of PAG Formation

not the real values of folic acid alone. Xanthopterin has an activity of as low as about $10^{-4}$ of folic acid to Streptococcus faecalis. It was fractionated in the following way. The reaction solution was adsorbed on Amberlite IR-4B and eluted with $\mathrm{NaCl}$ solution as described in experimental part. The fractionally eluted xanthopterin, $C F$ and folic acid were estimated with Leuconostoc citrovorum or fluorometrically or with Streptococcus faecalis fairly satisfactorily.

The result as given in Fig. 4 shows that the addition of xanthopterin alone to enzyme was almost the same as enzyme alone, but a remarkable folic acid synthesis took place in the system added with both xanthopterin and PAG. It is therefore clear that folic acid is biosynthesized from PAG and xanthopterin. But a fraction active for Streptococcus faecalis, differing from both folic acid and $\mathrm{CF}$, was also synthesized as shown in the Figure.

When the resin-treated enzyme was uesd, scarcely any folic acid was synthesized from PABA, L-glutamate and xanthopterin, but the synthetic activity was completely

Enzyme + PAG + xanthopterin

Enzyme + xanthopterin

$\square$ Enzyme

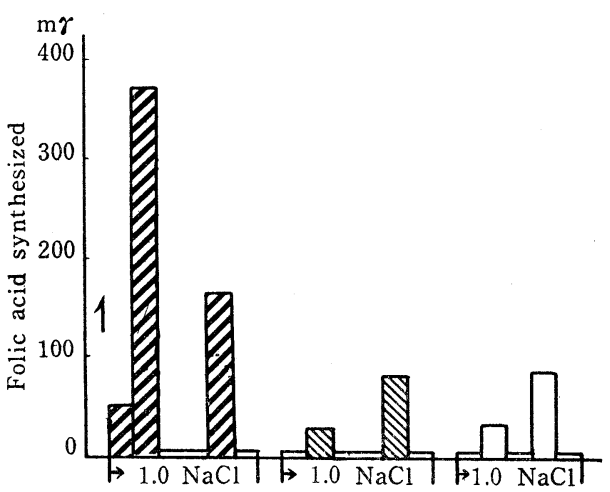

Fig. 4 Fractional Determination with Resin of Folic Acid Biosynthesized recovered after the addition of boiled bacterial extract to the enzyme. Thus the separation of active coenzymes from apoenzymes was accomplished by this method, as summarized in Table $\mathrm{V}$.

The optimum $\mathrm{pH}$ for the system, resin-treated enzyme plus boiled extract lies sharply at 7.2, whereas an unsharp maximum lies at about $\mathrm{pH} 6.5$ for resting cells.

When the relation of folic acid formed to enzyme concentration in the system of PABA, glutamate, and xanthopterin was compared with that in the system of PAG and xanthopterin, the yield of folic acid was by far higher in the case of PAG, as shown in Fig. 5, and was proportional to enzyme concentration, whereas in the case of the system of PABA and glutamate the 
TABLE V

Folic Acid Biosynthesis with Resin-Treated Enzyme

PABA, $0.29 \mathrm{~mm}$; L-glutamate, $0.58 \mathrm{~mm}$; xanthoterin, $0.056 \mathrm{~mm}$;

ATP, $0.84 \mathrm{~mm}$; resin-treated enzyme powder, $10 \mathrm{mg} / \mathrm{ml}$.

\begin{tabular}{c|c|c}
\hline Substrate & Cofactor & Amoutn of folic acid formed \\
\hline+ & - & $m \gamma / m l$ \\
+ & Boiled extract & 3.6 \\
- & Boiled extract & 84.9 \\
\hline
\end{tabular}

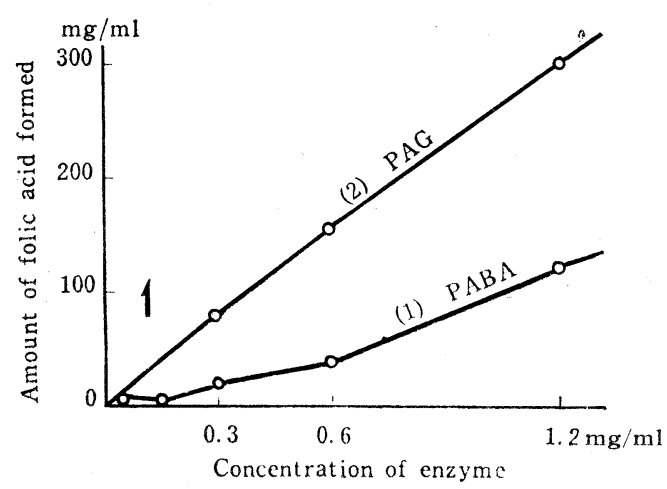

FIG. 5 Relation betwcon Enzyme Amount and the Amount of Folic Acid Formed from $P A B A$ and $P A G$

PABA, $0.58 \mathrm{~m} M$; glutamate, $1.16 \mathrm{~m} M$; xanthopterin, $0.056 \mathrm{~m} M$.

PAG, $0.58 \mathrm{~m} M$; xanthopterin, $0.056 \mathrm{~m} M$. yield was lower and was not proportional to enzyme concentration. Therefore, it was presumed that the pathway from PABA was more complicated than that from PAG, viz., the following pathway was assumed to exist from the experiments hitherto performed by the authors:

$\mathrm{PABA}+$ glutamate $\longrightarrow \mathrm{PAG} \longrightarrow$ folic acid

The coupling reaction of PAG with xanthopterin remains unsettled, and no analogous coupling reaction of the ring is known. It is therefore a problem of great interest.

As for folic acid synthesis, the pathway, in which the PAG moiety is linked simultaneously with the closure of pteridine ring is studied

by Forest $e$ t al. and Tsesche et al., whereas the possibility that PAG is formed from PABA plus glutamate and that folic acid is synthesized from PAG plus xanthopterin, was clarified by the authors enzymatically. Furthermore, in the former case the coupling of PABA with glutamate is an indispensable pathway, which has thus far been never analyzed.

Cohen et al. (7) proved the necessity of $\mathrm{CoA}$ for coupling of benzoic acid with glycine in hippuric acid synthesis, but no further analysis using hydroxamate fixation was made.

\section{SUMMARY}

1. The pathway of folic acid biosynthesis by the enzyme extracted from Mycobacterium avium is found to be the following: PABA and L-glutamate couple together to form $p$-aminobenzoylglutamate, which is then coupled with xanthopterin to form folic acid.

2. From the experiments using the resin-treated enzyme which is almost 
free from coenzymes, the coupling reaction of PABA and L-glutamate, a kind of peptide formation, requires ATP, CoA and $\mathrm{Mg}^{++}$as cofactors, whereby pyrophosphoric acid and AMP are liberated equimolecularly.

3. The amount of $p$-aminobenzoyl hydroxamate formed in this reaction is not reduced even when $\mathrm{CoA}$ is removed by resin treatment. It was presumed from this and other reasons that $p$-aminobenzoyl-AMP and $p$-aminobenzoyl$\mathrm{CoA}$ are the active intermediates of PABA.

4. A new method was devised for estimating folic acid alone applying the microbioassay using Streptocuccus faecalis to a fraction of Amberlite IR-4B. Using this method, folic acid was found to be synthesized from $p$-aminobenzoy 1 glutamate and xanthopterin.

5. The synthesizing enzyme of this step was found to be able to be divided into active apo-enzymes and co-enzymes by treatment with Amberlite IRA400 .

\section{ACKNOWLEDGEMENTS}

Thanks are due to Professor Hotta Kazuo and Dr. Yamamura Yuichi for their kind guidance. We are indebted to Messrs. M. Kawashima, and Y. Sugino for performing microbioassay.

\section{REFERENCE;}

1. Katunuma, N., Tuberculosis (Japan) 29, 413 (1954).

2. Katunuma, N., Ishikawa, E., and Yatarai, K., ibid. 30, 591 (1955).

3. Katunuma, N., Ishikawa, E., and Yatarai, K., ibid. 30, 538 (1955).

4. Doctor, V. M., and TrunneII, J. B., Proc. Soc. Exptl. Biol. Med. 87, 498 (1954).

5. Nichol, C. A., J. Biol. Chem. 207, 725 (1954).

6. Katunuma, N., and Shoda, T., Tuberculosis Congress, Tokai District Meeting, November 20, 1955.

7. Wright. L. D., and Welch, A. D., Science 98, 179 (1943).

8. Forest, R., and Walker, E. Nature 161, 721 (1948).

9. Carter, C. E., J. Am. Chem. Soc. 72, 1466 (1950).

10. Bratton, A. C., and Marschall, F. K., J. Biol. Chem. 128, 537 (1938).

11. Iwai, K., Vitamins 10, 372 (1956).

12. Lipmann, F., and Tuttle, L. C., J. Biol. Chem. 159, 21 (1945).

13. Kornberg, A., ibid. 182, 779 (1950).

14. Kaplan, N. O., and Greenberg, D. M., ibid. 156, 511 (1944).

15. Yagi, K., Vitamin Assay Method (Japanese) p. 84. Ishigaku Shuppan K. K., Tokyo (1954).

16. Cohen, P. P., and Mogilvery, R. W., J. Biol. Chem. 171, 121 (1947). 